\title{
Hazards in Hyperbaric Medicine
}

\author{
I. MCA. LEDINGHAM, ${ }^{*}$ M.B., CH.B. ; J. K. DAVIDSON, M.D., F.R.C.P.ED., F.F.R.
}

Cummary : During the period April 1965 to April 1968 observations were made on 285 patients and 357 stafi exposed to air and oxygen at pressures of 1 to 3 atmospheres absolute in a hyperbaric unit. Decompression sickness was not noted and an annual radiological skeletal survey failed to show aseptic bone necrosis; the incidence of otitic barotrauma was $4.7 \%$. Oxygen toxicity was not observed in any patient. It is suggested that pressures in this range are relatively safe in a specialized medical hyperbaric environment.

\section{Introduction}

Exposure to an environment of inoreased pressure, as in tunnel construction, caisson work, or deep-sea diving, is known to be associated with certain important hazards (McCallum, 1968). Among these are barotrauma, "nitrogen narcosis," and decompression sickness, including aseptic necrosis of bone. If, in addition to the increase in total gas pressure, the inspired oxygen concentration is also increased, oxygen toxicity may become a problem. Finally, there is an increased risk of fire in any environment with a raised oxygen pressure.

At the hyperbaric unit at the Western Infirmary, Glasgow, medical, nursing, and technical staff are exposed to air pressure up to 3 atmospheres absolute in the course of various investigative procedures designed to evaluate the therapeutic effectiveness of oxygen at increased pressure. This level of increased pressure of air is similar to that found in many civil engineering projects, and consequently the staff of the unit are liable to the same hazards as those working on commercial contracts.

This paper reports observations on staff and patients during the period April 1965 to April 1968. Oxygen toxicity is not discussed in detail, since the continuous exposure of patients to hyperbaric oxygen has been deliberately limited to periods of time not normally associated with the obvious clinical manifestations of this syndrome. The danger of fire, though important, is not discussed, since no information can be added to that already presented in several recent publications (Denison et al., 1968).

\section{Working Environment}

The hyperbaric unit has two compressed-air cylindrical steel chambers. The larger (30 ft. $(9 \cdot 1 \mathrm{~m}$.) in length by $15 \mathrm{ft}$. $(4.6 \mathrm{~m}$.) in diameter) comfortably accommodates a team of eight or nine personnel, and is used principally for surgical operations and various complex investigative procedures; the smaller (19 ft. $(5.8 \mathrm{~m}$.) in length by $10 \mathrm{ft}$. $(3 \mathrm{~m}$.) in diameter) is used for simpler procedures, and can accommodate four or five personnel. Both chambers have single terminal air-locks and are capable of attaining any required pressure from 1 to 3 atmospheres. During the last two years of the three-year study period a small one-man pressure chamber (capable of attaining 3 atmospheres) has also been available.

The research and therapeutic aspects of the unit's activities have been described in detail elsewhere (Ledingham, 1969).

\footnotetext{
* Senior Lecturer, University Department of Surgery.

+ Consultant Radiologist in Administrative Charge.

Western Infirmary, Glasgow W.1.
}

\section{Patients and Personnel}

Patients admitted to the pressure chambers for investigation or treatment included those suffering from various forms of ischaemia, hypoxaemia, and infection. Most received $100 \%$ oxygen, but a small number with advanced chronic respiratory disease were exposed to "air" at increased pressure. Patients in the two compressed-air chambers were not exposed to pressures exceeding 2 atmospheres; at pressures of 2 atmospheres or less the total period of continuous compression often exceeded 24 hours, but oxygen administration during this time was not continuous (Ledingham, 1967). In the one-man pressure chamber, with oxygen as the compressing gas, 2.5 atmospheres was the normal working pressure, often rising to the maximum of 3 atmospheres. The duration of continuous compression in the one-man chamber rarely exceeded two hours. Only patients who were to be anaesthetized before compression underwent myringotomy.

Included among the staff working in the two compressed-air chambers were clinical and non-clinical graduates, technicians, and nurses, with ages ranging from 18 to 45 years, the great majority being under 35 years of age. The bulk of the work fell on a relatively small number of personnel whose exclusive responsibility was to the hyperbaric unit for at least one yearreferred to hereafter as long-term staff. Before their first exposure to pressure the latter were questioned about their past medical history, with specific inquiry concerning any preexisting disease affecting the ears, upper respiratory tract, and lungs. They were further required to have radiographic examination of the chest and shoulder, hip, and knee joints, these examinations being repeated at annual intervals. In a few instances electrocardiographic records and a complete ear, nose, and throat examination, including audiography, were made. The remainder of the personnel included nurses from the general nursing pool who helped with the care of patients receiving long-term treatment in the pressure chamber, attendant medical staff, and visiting research workers from other centres. These persons, though large in total number, individually spent only a short time at increased pressure. They had a medical examination similar to that of the permanent staff except that a skeletal radiographic examination was not made unless they were to be exposed to pressures exceeding 2 atmospheres.

Precautions were taken to exclude those who had a definite history of acute or chronic ear, nose, throat, or lung conditions. Radiographic evidence of pulmonary disease precluded any exposure to compressed air, possible exceptions being those with a small calcified focus in the upper lobes of the lungs.

All potential members of the staff were subjected to a test compression to exclude any who could not satisfactorily achieve pressure equilibrium between the environment and their air cavities. Once accepted, all permanent members of staff were given a short course of instruction covering the relevant aspects of work in compressed air.

\section{Decompression Programme}

Each compression and decompression was controlled and recorded in a log-book by one of the permanent staff of three compressed-air engineers. Any untoward symptoms experienced by the hyperbaric personnel were also recorded. Initially 
the decompression schedules for all exposures, whether'more or less than four hours, followed the schedule set out in the Work in Compressed Air Special Regulations (Ministry of Labour and National Service, 1958). Subsequently the schedule was lengthened for all exposures over four hours, and followed the Blackpool Trial Tables (1966) (McCallum, 1968). These trial tables were prepared by the Medical Research Council Decompression Sickness Panel, and have been used on a number of compressed-air civil engineering contracts.

In practice a decompression schedule was not used for pressures of 2 atmospheres or less; the rate of decompression from this level of pressure, irrespective of the duration of exposure, was such as to ensure the comfort of the patient and staff. During decompression from pressures exceeding 2 atmospheres two additional measures were incorporated into the Glasgow programme. (1) A stop of at least five minutes was made at 2 atmospheres whether required or not according to the decompression tables. (2) Oxygen breathing via a special mask system (McDowall et al., 1965) was begun five minutes before the start of decompression and continued without interruption until a pressure of 1.5 atmospheres was reached; during the "slow" phase of decompression from 1.5 to 1 atmospheres oxygen was not breathed.

Compression to pressures exceeding 2 atmospheres on consecutive days by the same individual was almost entirely avoided.

The rate of decompression in the one-man pressure chamber - compressed as it was with oxygen-was determined solely by the requirements for the patient's comfort. The duration of decompression was normally 10 to 15 minutes from a maximum pressure of 3 atmospheres.

\section{Results}

During the three years under review there was a total of 3,776 compressions involving 285 patients and 357 staff. Table $I$ indicates the division of these figures on a yearly basis: the exposure of a small number of the staff in each of the three years accounts for the discrepancy between the total of 357 and the sum of the individual years-383. In the two years of its use 33 patients were treated in the one-man chamber, with. a total of 209 compressions.

TABLE I.-Number of Staff and Patients Exposed Per Annum to 2 and' TABLE 1.-Number of Staff and Patients Expo
3 Atmospheres

\begin{tabular}{lll|c|c|c} 
& & $1965-6$ & $1966-7$ & $1967-8$ \\
\hline Patients at 2 atmospheres & $\ldots$ & $\ldots$ & 84 & 93 & 108 \\
Staff at 2 atmospheres & $\ldots$ & $\ldots$ & 103 & 121 & 120 \\
Staff at 3 atmospheres. &. &. & 13 & 15 & 11 \\
\hline
\end{tabular}

Table II outlines the number and duration of exposures: among the staff on an average annual individual basis. The 2 and 3 atmosphere pressure levels are considered separately, as are the data for the long-term staff. The average duration of exposure per person varied little at either of the two pressure ranges, and the long-term staff had a comparable duration of exposure. Compared with the average for all staff, however, the long-term staff had almost five times the number of com-

TABLE II.-Number and Duration of Exposures at 2 and 3 Atmospheres

\begin{tabular}{|c|c|c|}
\hline & 2 atmospheres & 3 atmospheres \\
\hline 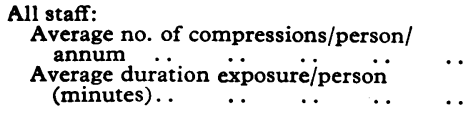 & & \\
\hline 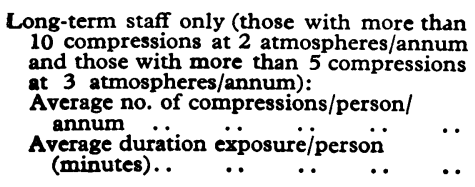 & $\begin{array}{r}42 \\
125\end{array}$ & $\begin{array}{r}19 \\
182\end{array}$ \\
\hline
\end{tabular}

pressions per person per annum at 2 atmospheres and three times the number of compressions per person per annum at 3 atmospheres.

These data are amplified in Figs. 1, 2, and 3. At 2 atmospheres, 261 staff and visitors had fewer than five exposures to pressure, and one person had 168 exposures; at 3 atmospheres 27 staff had fewer than five exposures, and one had 45 exposures (Fig. 1). The maximum duration of exposure at 2 atmospheres was 530 minutes (Fig. 2), and there were 54 exposures of more than four hours. At 3 atmospheres (Fig. 3) the maximum exposure was five hours, and there were five exposures of more than four hours.

Many of the staff and patients experienced discomfort in the ears during compression, but in only 17 out of 357 staff $(4.7 \%)$ was earache severe enough to prevent attainment of the required
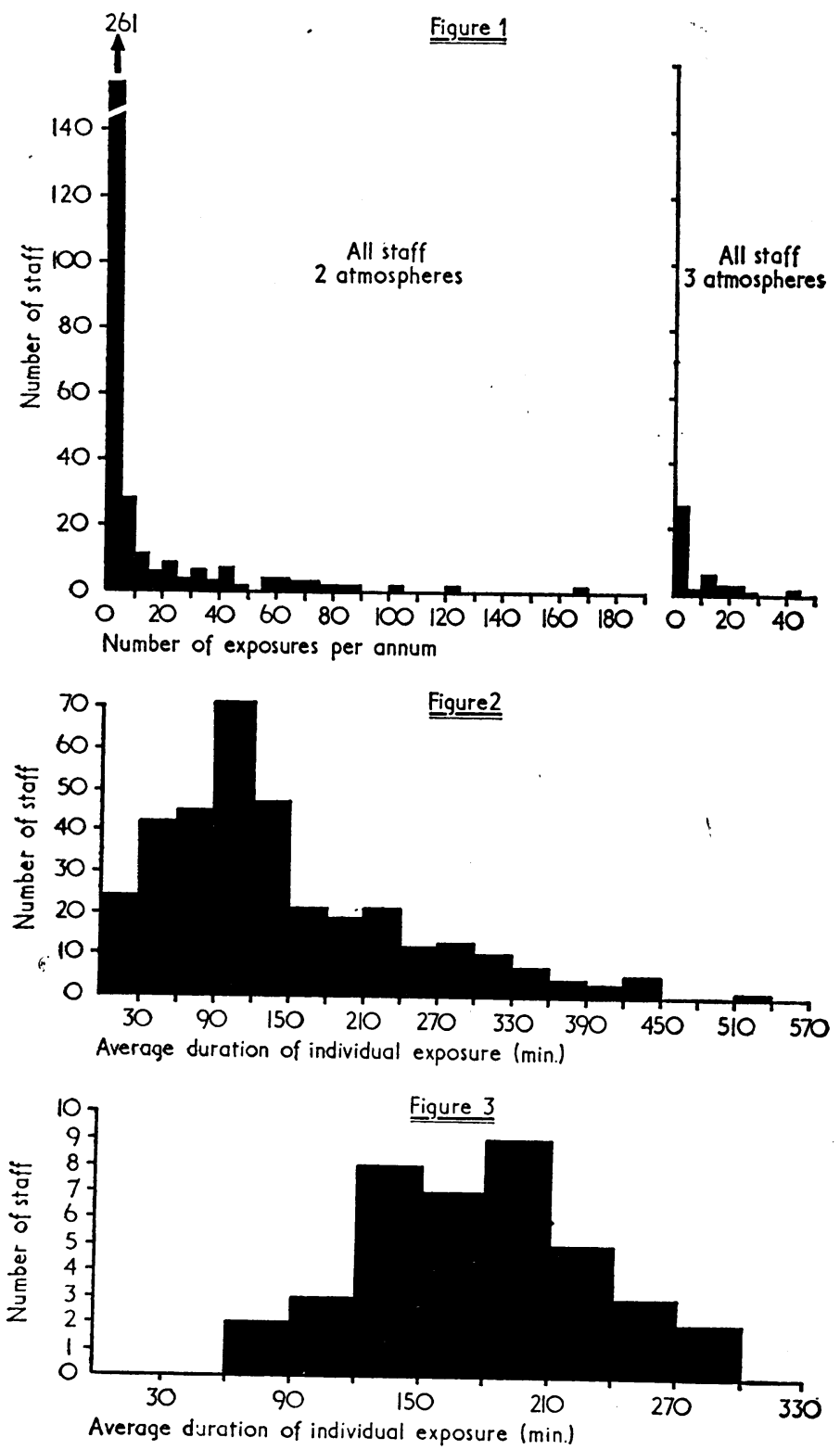

Fig. 1.-Number of exposures per person per annum at 2 and 3 atmospheres.

Fig. 2.-Duration of exposure per person at 2 atmospheres. FIG. 3.-Duration of exposure per person at 3 atmospheres.

pressure. No patient was prevented from reaching the required pressure because of earache. All those who developed serious earache were subsequently subjected to a full ear, nose, and throat examination, including in most instances an audiogram; in none was there evidence of rupture of the tympanic membrane or of permanent damage to any other aural structure. 
Discomfort and pain in other air-containing cavities during compression were very much less frequent than earache; during decompression very few untoward symptoms of any sort were experienced.

So-called " nitrogen narcosis," taking the form of mild euphoria and an inability to perform mathematical calculations rapidly and accurately, was often experienced during the first few exposures to pressures greater than 2 atmospheres. These sensations appeared to diminish with further experience.

Pain resembling type 1 decompression sickness ("the bends") was never recorded, and no member of staff experienced the potentially more serious type 2 decompression sickness. Thirtysix members of staff, including all those exposed to pressures exceeding 2 atmospheres, had an annual skeletal radiological examination of the shoulder, hip, and knee joints. In 21 of the 36 sufficient time (at least one year to four years and six months) elapsed between the first exposure to pressure and the last radiographic examination to permit the radiographic demonstration of aseptic necrosis of bone. None showed any evidence of aseptic necrosis.

Oxygen toxicity is of ten difficult to diagnose because of its non-specific nature. In the present study, however, any signs and symptoms in a patient receiving hyperbaric oxygen treatment which might have been attributable to oxygen overdosage could usually be explained more satisfactorily by the primary condition from which the patient was suffering. In particular, no patient convulsed even among those exposed to 3 atmospheres of oxygen in the one-man chamber for more than two hours. No member of the staff convulsed in spite of the routine practice of breathing a high concentration of oxygen for five minutes before decompression from pressures exceeding 2 atmospheres.

\section{Discussion}

Reports of early observations on staff from the hyperbaric unit at Duke University Medical Center (Anderson et al., 1964) and Copenhagen (Paulev, 1966) have been published. McCallum (1968) published a review of the dangers of hyperbaric pressures to tunnel workers.

Comparison of the results from different hyperbaric environments must necessarily take cognizance of the many variables - the length and number of exposures, the maximum working pressure, the interval between repetitive exposures, and the form of the decompression programme. At Duke 1,516 decompressions were carried out by 62 medical personnel from pressures varying from less than 2 atmospheres to a maximum of 5 atmospheres, over $50 \%$ being at 3 atmospheres. The mean exposure time was 62.5 minutes, and the decompression programme followed the U.S. Navy Diving Tables, which were later modified to include oxygen breathing. In Copenhagen the duration of exposure was less than 60 minutes at $2 \cdot 8$ atmospheres-within the " no decompression" or " minimal decompression" limitation of the U.S. Navy Diving Tables. Compared with hospital staff, tunnel workers are exposed much more often and the periods of exposure are considerably longer-the shift period on most civil engineering contracts being eight hours. On the Clyde Tunnel contract there were 240,259 decompressions by 1,362 men from a maximum pressure of 3.5 atmospheres over three and a half years, and at the Dartford Tunnel there were 122,000 decompressions by 1,200 men from a maximum of 3 atmospheres over two years. The decompression schedules on these contracts followed the Work in Compressed Air Special Regulations (Ministry of Labour and National Service, 1958), and did not include oxygen breathing.

At the Western Infirmary there were 3,776 decompressions of 357 members of staff, frcm a maximum pressure of 3 atmospheres-the mean exposure time at the maximum pressure was 178 minutes. The difference between the various decompression tables for such an exposure time is shown in Table III. In particular, the Western Infirmary programme includes oxygen breathing and a stop at 2 atmospheres additional to the requirements contained in the U.K. 1958 Regulations, but the total decompression time remains considerably less than that of any of the other three programmes.

TABLE III-Decompression Procedures in Use in the U.K. and the
U.SA. 178 Minutes at 3 Atmospheres

\begin{tabular}{|c|c|c|}
\hline & Decompression Procedures & $\underset{(\text { min. })}{\text { Total time }}$ \\
\hline $\begin{array}{l}\text { U.K.: } \\
1958 \text { Regulations } \\
\text { R.N. Diving Tables } \\
\text { Blackpool Trial } \\
\text { Tables } \\
\text { Western Infirmary, } \\
\text { Glasgow } \\
\text { U.S. Navy Tables }\end{array}$ & $\begin{array}{l}\text { Quickly initially: one stop at } 1.5 \\
\text { atmospheres } \\
\text { Quickly initially: three stops at } 1.9 \\
1.6 \text {, and } 1.3 \text { atmospheres } \\
\text { Stops at } 1.8,1.5 \text {, and } 1.3 \\
\text { atmospheres } \\
\text { Quickly initially: two stops at } 2 \text { and } \\
1.5 \text { atmospheres-oxygen breathing } \\
\text { Quickly initially: two stops at } 1.6 \\
\text { and } 1.3 \text { atmospheres }\end{array}$ & $\begin{array}{r}50 \\
100 \\
105 \\
60 \\
121\end{array}$ \\
\hline
\end{tabular}

During compression, failure to equalize pressure in the middle ear and other air-containing cavities can cause discomfort and pain. The figure of $4.7 \%$ found in this study agrees with the report published by the National Research Council Committee on Hyperbaric Oxygenation (1966), which stated, "approximately $5 \%$ of the general population cannot successfully equalize pressure." Behnke (1940), Anderson et al. (1964), and Paulev (1966), however, found a higher incidence of this complication-around $12 \%$. No permanent sequelae on ear, nose, and throat examination were noted in the 17 affected persons in the Glasgow series.

Symptoms of so-called " nitrogen narcosis" were almost universal when an individual experienced his first exposures to pressures exceeding 2 atmospheres. The retrospective study at Duke suggested that "nitrogen narcosis" was relatively infrequent in experienced personnel, as only 11 of the 62 members of the Duke team felt that there was danger of making an experimental error. The effects of a high-pressure environment on higher cerebral function have been examined in two recent studies utilizing card-sorting manœuvres. The first, on tunnel workers (Poulton et al., 1963), showed that the performance of these workers was adversely affected at 2 atmospheres, but only while the task was being learned. The same experiment repeated at the Royal Naval Physiological Laboratory showed no such abnormality (Bennett et al., 1967).

After decompression, and occasionally during the later stages of decompression from raised environmental pressure, decompression sickness may occur-either type 1 , "simple bends," or the potentially more dangerous type 2, with pulmonary, cardiac, ophthalmic, or neurological symptoms and the possibility of shock or coma. In tunnel workers decompression sickness can be recorded only if the symptoms are severe enough to cause a man to return to the medical centre for therapeutic recompression. The incidence is usually recorded as a percentage of all decompressions from over $2 \cdot 2$ atmospheres, and was $0.29 \%$ at the Clyde and $0.93 \%$ at the Dartford Tunnel. At the Tyne Tunnel contract the incidence was expressed as $1.5 \%$ of all decompressions. These figures included both type 1 and type 2 . Type 2 cases were comparatively infrequent, the average incidence being about $0.04 \%$ of decompressions.

Experience at the hospital hyperbaric units at Duke University and Copenhagen, and now at the Western Infirmary, Glasgow, showed that therapeutic recompression was never required, and so, by the definition as used for tunnel workers, there were no cases of type 1 or type 2 decompression sickness. Some minor symptoms were noted at Duke University Center, but after the introduction of oxygen breathing during decompression there were no further cases. Some of the Glasgow staff experienced the "odd pain," careful records of which were not kept. It is difficult to attach any significance to these pains, since they did not appear to differ either in frequency or in severity from those which are present in everyday life.

Recently it has been suggested that pulmonary "air trapping" during decompression may lead to cyst formation and 
rupture causing air embolism, and this might be the cause of the more serious type 2 decompression sickness (Walder, 1963). For this reason routine chest radiographs are advised on all hospital personnel before working in a hyperbaric environment. It is suggested that the examination should include radiographs on expiration and full inspiration to see if any localized overinflation could be found. Patients who were seen to have cysts or bullae of their lungs should be excluded from work in compressed air. Where routine chest radiographs were carried out in tunnel workers on the Clyde and such cases were excluded, there was apparently no reduction in the incidence of type 1 or type 2 decompression sickness (Davidson, 1964).

No abnormalities were noted on the chest radiographs of the Glasgow staff other than small calcified foci on two occasions. In these two subjects no change in the appearance of the chest radiograph was noted after frequent exposures to hyperbaric pressure. Moreover, in another series of studies more than 50 patients with advanced chronic respiratory disease were decompressed from pressures not exceeding 2 atmospheres without untoward consequences-one such patient had 26 compressions over a period of three years (Ledingham et al., 1968).

Aseptic necrosis of bone is a late sequel of working in compressed air, and radiographic changes may not appear until 6, 12 , or 18 months after the causative episode. When the bone lesion is next to a joint surface, as in the head of the femur or the head of the humerus, permanent disability may result. An extensive study of 241 tunnel workers at the Clyde Tunnel showed that $19 \%$ of the men had one or more bone lesions and that in $10 \%$ lesions were juxta-articular and so potentially disabling.

Among hospital personnel and those responsible for their safety there was concern that disabling bone lesions might develop. It is true that compared with tunnel workers the number of staff involved in medical hyperbaric environments is small, and the duration and number of exposures much less. In 21 of the 36 members of the staff examined radiologically, however, sufficient time has now elapsed for a bone lesion to have appeared; fortunately no radiological indication of any such lesion has emerged. So far as we are aware no comparable radiographic study at other hospital hyperbaric units has been reported.

These data at present support the claim that pressures of air in the range 1-3 atmospheres are relatively safe for use in a specialized medical hyperbaric environment. It remains entirely conjectural whether the modifications added to the conventional decompression programmes, such as the breathing of oxygen and the introduction of extra stops during decompression, have had any bearing on these findings.

\section{REFERENCES}

Anderson, B., jun., Whalen, R. E., and Saltzman, H. A. (1964). Fournal of the American Medical Association, 190, 1043

Behnke, A. R. (1940). Annals of Internal Medicine, 13, 2217

Bennett, P. B., Poulton, E. C., Carpenter, A., and Catton, M. J. (1967). Ergonomics, 10, 53 .

Davidson, J. K. (1964). Clinical Radiology, 15, 106.

Denison, D. M., Ernsting, J., Tonkins, W. J., and Cresswell, A. W. (1968). Nature, 218, 1110 .

Ledingham, I. McA. (1967). In Modern Trends in Pharmacology and Therapeutics, p. 96, edited by W. F. M. Fulton. London, Butterwherap

Ledingham, I. McA. (1969). In Recent Advances in Surgery, 7th ed., p. 45 , edited by S. Taylor. London, Churchill.

Ledingham, I. McA., Spence, A. A., Tindal, S. A. P., and Mone, J. G. (1968). Unpublished data.

McCallum, R. I. (1968). British fournal of Industrial Medicine, 25, 4. McDowall, D. G., Ledingham, I. McA., Jacobson, I., and Norman, J. N. (1965). Anesthesiology, 26, 720.

Ministry of Labour and National Service (1958). Work in Compressed Air Special Regulations (S.1. 1958, No. 61). London, H.M.S.O.

National Research Council, Committee on Hyperbaric Oxygenation (1966). Fundamentals of Hyperbaric Medicine. Washington, National Academy of Sciences.

Paulev, P. (1966). Danish Medical Bulletin, 13, 49.

Poulton, E. C., Carpenter, A., and Catton, M. J. (1963). British Medical fournal, 2, 1450.

Walder, D. N. (1963). In The Regulation of Human Respiration, p. 570 , edited by D. J. C. Cunningham and B. B. Lloyd. Oxford, Blackwell Scientific Publications.

\title{
Scintillation Scanning of Lungs in Preoperative Assessment of Carcinoma of Bronchus
}

\author{
R. H. SECKER WALKER,* M.B., M.R.C.P. ; J. L. PROVAN, † M.s., F.R.C.S.
}

[With Special Plate between Pages 330-331]

Cummary : Lung scans with the use of macroaggregated $\checkmark$ human serum albumin labelled with technetium-99m were carried out in 52 patients before thoracotomy.

Forty-three patients had carcinoma of the bronchus. Tumours less than $2 \mathrm{~cm}$. in diameter on the chest radiograph were not detected. Larger tumours showed defects in perfusion, ranging in size from the mass seen on the chest radiograph to almost absent perfusion of the entire lung. The extent of the defect in perfusion was closely related to involvement of the pulmonary vessels at the hilum by distortion, compression, or invasion by the tumour. Bronchial obstruction played a less important part in producing the defects.

The larger the defect in perfusion the greater was the involvement of the hilar and mediastinal structures and the more extensive was the surgery required. When perfusion of the affected lung was less than one-third of the total the tumour was found to be unresectable.

\section{Introduction}

About one-third of the patients with carcinoma of the bronchus undergoing thoracotomy are found to have an unresectable tumour (Gifford and Waddington, 1957 ; Price Thomas, 1960 ; Flavell, 1962 ; Barrett et al., 1963 ; Belcher and Anderson, 1965). In such cases resection is prevented by extensive spread of the disease or invasion of vital structures. Some indication of the extent of involvement of the hilar region may be seen on the chest radiograph or demonstrated by tomography. In a few centres angiocardiography has been used to show involvement of the great vessels, and this technique has proved useful in determining resectability in some instances (Wyman and Wilkins, 1958 ; Steinberg and Finby, 1959).

\footnotetext{
* Lecturer in Medicine, University College Hospital Medical School, London W.C.1.

† Senior Lecturer in Surgery, University College Hospital Medical School, London W.C.1. Present address: Department of Surgery, the Wellesley Hospital, 106 Wellesley Street East, Toronto 5, Ontario, Canada.
} 